\title{
Microsatellite Instability
}

National Cancer Institute

\section{Source}

National Cancer Institute. Microsatellite Instability. NCI Thesaurus. Code C36318.

Genomic instability associated with the presence of hypermutability in specific genetic marker regions resulting from defective DNA mismatch repair. 